\title{
Optimization of Role of Coach in The Basic Value of Civil Apparatus Actualization Professionals Candidate Apparatus on Civil Government in The City of Samarinda
}

\author{
Endang Tri Wahyuningsih ${ }^{1}$, Dewi Sartika ${ }^{2}$ \\ ${ }^{1}$ Regional Civil Service and Education and Training Agency Samarinda, Indonesia \\ ${ }^{2}$ Center for Training and Development and Study of Decentralization and Regional Autonomy \\ National Institute of Public Administration, Indonesia \\ Email:naurah10@yahoo.com
}

\begin{abstract}
This study aims to find out how to optimize the role of coaches to actualize the basic values of Candidate Civil Servants in Samarinda City Government Environment. The research method used is a quantitative approach, where data collection is obtained from primary data through a survey with a questionnaire instrument for respondent coaches and trainees. A total of six categories of questions were addressed to trainee respondents and six open questions addressed to coaches. The results of the study after analysis are that the role of the coach in carrying out the role of coaching and mentoring towards participants is quite high. However, some things that need to be optimized from all of these categories. respondents who answer sometimes, sometimes not as many as 1 to 3 people.
\end{abstract}

Keywords: Coach, The Actualization of the Basic Values of the Profession, Civil Servants Candidate, Regional Government of Samarinda City.

\section{A. INTRODUCTION}

The pre-service education and training are aimed at forming professional civil servants, namely civil servants whose characters are formed by three competencies, namely: the basic values of the civil servant profession, attitude and discipline of civil servants, and knowledge of the position and role of civil servants in the Unitary State of the Republic of Indonesia, to be able to carry out their duties and roles professionally as public servants.

To be able to form a strong civil servant character, namely civil servants who uphold the standards of public ethics in carrying out their duties, it is necessary to hold an innovative Pre-service Education and Training, namely the implementation of Preservice Training which allows participants to be able to internalize these competencies, experience for themselves in implementing and actualizing them on the spot. work, feel the benefits so that the three competencies are embedded in him as daily attitudes and behaviours.

To find the originality of this research, the following previous studies with the same discussion theme are presented below: 
Table 1. Comparison of Originality

\begin{tabular}{|c|c|c|c|}
\hline Authors, Titles, Years & Similarity & Differences in & Originality \\
\hline $\begin{array}{l}\text { Pentingnya } \\
\text { Pendampingan dan } \\
\text { Evaluasi Pasca Diklat } \\
\text { terhadap Aktualisasi } \\
\text { Peserta Pelatihan Dasar } \\
\text { (BPSDM, 2018) }\end{array}$ & $\begin{array}{l}\text { This research } \\
\text { emphasizes the role of } \\
\text { mentoring and post- } \\
\text { training evaluation on } \\
\text { the actualization of } \\
\text { basic training } \\
\text { participants. }\end{array}$ & $\begin{array}{l}\text { If this research uses the } \\
\text { observation method and } \\
\text { literature study, the } \\
\text { author's research uses } \\
\text { the survey method. } \\
\text { (distributing } \\
\text { questionnaires) }\end{array}$ & $\begin{array}{l}\text { The actualization of the } \\
\text { basic values of basic } \\
\text { training participants is } \\
\text { determined, one of } \\
\text { which is the role of the } \\
\text { coach in achieving the } \\
\text { expected goals. }\end{array}$ \\
\hline $\begin{array}{l}\text { Optimalisasi } \quad \text { Peran } \\
\text { Widyaiswara dalam } \\
\text { pelaksanaan Pendidikan, } \\
\text { Pengajaran dan Pelatihan } \\
(\text { Triati, 2019) }\end{array}$ & $\begin{array}{l}\text { This study both used } \\
\text { the questionnaire } \\
\text { distribution method } \\
\text { (evaluation) } \\
\text { Literature }\end{array}$ & $\begin{array}{l}\text { study This research } \\
\text { looks at the role of } \\
\text { educators in realizing } \\
\text { education and training } \\
\text { outcomes, while the } \\
\text { author's research looks } \\
\text { at the role of educators } \\
\text { in realizing the basic } \\
\text { values of training } \\
\text { participants }\end{array}$ & $\begin{array}{l}\text { This research evaluates } \\
\text { the role of coaches in } \\
\text { mentoring and } \\
\text { actualizing the value of } \\
\text { basic education and } \\
\text { training participants }\end{array}$ \\
\hline
\end{tabular}

Source: (BPSDM, 2018); (Triati, 2019)

From the results of the previous study above, some very basic points of difference with this research include:

1. This research study describes optimizing the role of trainers (both from trainee, leaders, and other education and training managers) in actualizing the basic values of basic training participants

2. This research focuses on the category of commitment towards developing task completion; assessment, diagnosis, and planning; face-to-face meetings and provide feedback; concern; listen and respond; and implementation and followup.

The results of the study (Suyono, 2015) explained that activities coaching illustrated that the average score of participants for Innovation Planning was 81.89, the frequency of consultation for training participants in actualizing change projects was $82.7 \%$, the frequency of consultation for activity stages was 82.5 . \% and the average value of Change Management were 82.24. The results of the study generally show that activities coaching can improve the competence of training participants in preparing Innovation Planning and Change Management.

Djoka (2018), shows that several recommendations that need to enforce the implementation of training curricula/materials by the provisions of laws and regulations, it is necessary to condition and increase the motivation of pre-service training participants to support training objectives, it is necessary to increase the ability of lecturers as educators, teachers, and pre-service training trainers, it is necessary to select and apply pre-service training learning methods by the training material 
provided to pre-job training participants, and the fulfilment of training infrastructure and facilities to support the successful implementation of pre-service training.

The renewal of the Pre-service Education and Training was marked by nonclassical learning (off-campus) through the actualization of the basic values of the civil servant profession. Actualization is a learning stage which is essentially guiding participants in actualizing the basic values of the apparatus profession in the workplace by the coach. Besides, in connection with the changes Regulation in the choice of classical lesson hours from 12 lesson hours to 9 lesson hours which is classical and 3 lesson hours is e-learning. This reinforces the importance of the role of the Coach in guiding on the actualization of basic training participants because of the reduction in classical learning. The focus of this research is to see the role coach's in actualization guidance. Given the extent of the problem, Research on the implementation of research is only to see the optimization of the role coach's in guiding the actualization of apparatus candidate basic training in the Samarinda City Government, East Kalimantan Province. The aim that the researcher wanted to obtain in this study was to find out how to optimize the role of the coach in actualizing the basic values of the civil servant profession at apparatus candidate basic training in Samarinda City Government Environment. Based on the background in this study, the following problems were formulated, namely how to optimize the role of the coach in actualizing the basic values of the civil servant profession on apparatus candidate basic training in Samarinda City Government Environment?

The competencies that want to be built in the pre-service education and training are the competence of civil servants as professional public servants, which is indicated by the ability to actualize five basic values, namely to internalize the basic values of the profession which are synchronized with the term "ANEQA", namely 5 teaching materials Accountability, Nationalism, Ethics, Quality and Anti-Corruption.

The evaluation stage is carried out twice, namely the evaluation of understanding which will be carried out after the participants have completed the ANEQA learning in class before the guidance is compiling the actualization plan for the Basic Values of the Civil Servants in the workplace and the actualization evaluation which will be carried out after the participants have completed the actualization learning in the workplace by presenting the design and the achievement of actualization results in the workplace in front of examiners, supervisors, and supervisors of the participants.

Assessment of the graduation of Pre-service Training Participants is focused on the components of understanding and actualization of the Basic Professional Values of Civil Servants, with a proportion of $30 \%$ and $70 \%$. Assessment of the understanding of Basic Values is carried out through a written exam which can be in the form of multiplechoice, true-false, matchmaking, short answers, and essays. Mastery of understanding of the Basic Values of the Apparatus Profession is shown through the answers of the 
Pre-Service Training participants in a written exam that is carried out after all the training courses for the Basic Values of the Apparatus Profession are given.

The assessment indicator for the actualization component of the Basic Values of the Civil Servant Profession (70\%) includes the actualization design and actualization of the Basic Values, with a proportion of $15 \%$ and $55 \%$. The final evaluation is carried out by taking into account the results of the evaluation of the components of understanding and actualization of the Basic Values of the Apparatus Profession. The value of understanding and actualization of the Basic Values of the Civil Servant Profession is recapitulated according to their respective weighting to produce the final score. The passing qualification is determined by the limit passing grade is over 70 (seventy). The qualifications for passing the training participants are determined from the lowest score of Not Satisfactory $(<60)$ to the highest score of Very Satisfactory $(>90-100)$. Training participants who obtain the unsatisfactory qualifications or the number of absentee participants exceeding 3 sessions or 9 hours of lessons or one day cumulatively are declared Not Passing. While Training Participants who obtain the qualifications are Not Satisfactory is declared to have their graduation postponed and those Training Participants are required to take remedial learning.

Through various ANEQA learning activities, participants are required to have an understanding and awareness to have the essence of basic values as a set of principles that form the basis for carrying out the profession as a Civil Servant. Armed with a deep understanding, participants are expected to be able to actualize the five basic values contained in the training program. The word "actualization" itself comes from the word "root actual" which means real/happened/exists. Therefore, the actualization of basic values can be interpreted as a process to make the five basic values actual/real/occur/exist, not limited to understanding or mastering the concept of basic values cognitive elements) but at the level of applicative. A complete understanding of the five basic values of the Apparatus profession raises awareness of the relationship between these basic values and every practice of implementing civil servant duties.

The actualization of the basic values of the civil servant profession to be carried out properly begins with a plan to actualize the five basic values and is outlined in a learning document called the basic value actualization plan. The contents of the actualization design are essentially the points of the activity plan that will be carried out while they're at the place of assignment/internship. In every activity, it is demanded that the activity contains the actualization of one or several basic values of the civil servant profession. The quality of the design is not only the presentation format but also the content or content elements. It must be remembered that the activities included in the actualization design are the object of the evaluation of the Examiner, Coach, and Mentor.

The draft actualization of the basic values of the civil servant profession that has been compiled is essentially a temporary document. The new design is an agreement 
between the participants and the Coach. The examiners and mentors were not involved in the drafting process. Examiners and Mentors must be involved and take part in the drafting process before it is determined as a final design. Their input and criticism in the seminar are very important to finalize and perfect the actualization design.

Then go to the actualization stage (off campus) where participants are required to work, carry out certain tasks, which allow participants to experience firsthand how the basic values of the civil servant profession are applied. The method is taking place experiential learning, where participants work real or real, not as if or playing roles. From this real work, it is hoped that a deeper learning process will occur so that it is imprinted in the Participants' minds.

For the experiential learning process to run effectively, three things need to be considered and implemented, namely: how to build smooth communication with Mentors and Coaches including the organizers of the Education and Training, how to document all the activities that have been agreed upon during the actualization design seminar, and how to compile an actualization report. Through these three things, the actualization report which is a learning product at the actualization stage will be more guaranteed.

A very global language, Coaching is defined as "Coaching, teaching, instructing, advising the team or person to achieve certain goals." In coaching, coaches do not provide solutions for Coachee but guide them to find solutions through digging from within themselves (Aji, 2017). (Jarvis, 2008) defines coaching as developing a person's skills and knowledge so that their performance will improve, and lead to the achievement of organizational goals. A coach effective does not teach or instruct anything, nor give advice or solutions for Coachee (Coachee = people in coaching). However, they are still able to help their Coacheeto learn and grow by asking questions. Of course not just any question. But questions that can spark self-awareness and provoke creative action. This is nothing new. Centuries ago Socrates had started. Unfortunately, however, the Socratic method is gradually being forgotten.

More or less the same thing (Glcworld.co.id, 2020) defines a coach as a coach and a Coachee as a person who is trained who is generally a business owner or leader and executive at large companies in the process coaching or providing instruction, guidance, or intensive training. The Coach helps Coachee to be more effective and efficient in the process of achieving it. The dominant technique used in coaching is questioning, namely asking. Through questions, Coachee is guided to explore the potential that exists in him, so that (1) find a strong reason as a solid foundation for his development. Not only that, coach (2) teaches the Coachee to strategize to achieve his goals. At the same time, (3) the coach ensures that Coachee carries out what has been planned and is committed to the rewards and consequences, rewards himself for achievements, and carries out the consequences for failures. Do not forget that a Coachee will (4) help the Coachee grow and 
develop into a competent, independent individual without dependence on the coach in the future.

In the last few decades, involvement is coaching very important to build organizational capabilities and develop trends in organizational development programs. The definition of coaching itself varies both based on a philosophical approach underlying it, the contextual focus, or the purpose of coaching itself. According to BaekKyoo (Fraser, 2007), coaching is described as a form that is organizationally related to development which includes professional and personal abilities. Rosinski (Kimball, 2018), assesses that coaching is an art in helping to unleash one's potential to achieve important and meaningful goals. Armstrong (2014), stated that coaching is a personal (usually one by one) approach to work to help someone develop their abilities and levels of competence.

National Institute of Public Administration (LANRI, 2020) defines coaching as a process of guidance to improve performance and competence between coaches, in this case, officials/professionals appointed by talents/successors or employees who need a coach to complete tasks assigned by the leadership (through the provision of problemsolving skills, optimize self-potential).

From some of the above meanings, the concept of coaching is a fundamental process carried out on someone who aims to develop competencies that are closely related to learning.

In terms of basic training, coaching is an interrelated and inseparable part. In Head of Regulation Number 21 of 2013 concerning Guidelines for the Implementation of Education and Training for Civil Servant Class III Candidate Apparatus, at the point summary of the training for guidance in the workplace (Coaching) explains briefly that guidance is carried out by submitting requests for guidance to the coach, to discussions using communication technology and electronic-based information so that participants regain the competencies needed in actualizing the basic values of the Apparatus profession, attitude, and discipline of civil servant behaviour and knowledge of the position and role of civil servants and the Republic of Indonesia.

Furthermore, at the point of consultation in the workplace (counselling) explains briefly that consulting begins with carrying out the actualization stage at his workplace, submitting a counselling request to the coach, to discussing and getting counselling from the coach using electronic-based communication and information technology so that participants have a motivation to apply the basic values of the civil servant profession, the attitude and discipline of civil servants and knowledge of the position and role of civil servants in the Unitary State of the Republic of Indonesia.

\section{B. METHOD}

The method used in this research is method descriptive study. Descriptive research studies begin with a well-defined problem or question and try to explain it accurately. 
The results of the research are in the form of a detailed description of the problem or the answer to the research question.

In qualitative research with the method descriptive study, this study can see the indepth condition of various related information and present a specific picture of the role of coaches in actualizing the basic values of the civil servant profession by using accurate data sources used to assess and answer problems that become research sub-focus.

The data source of this research is key informants who are considered capable of providing information in connection with exploring the role of the Coach in the guidance of candidate apparatus basic training in the Samarinda City Government, namely all the Coaches in 4 batch taken using a population sample, and Participants from 4 batch taken using random samples as many as 4 people per batch with a total of 16 people, this is done with the assumption that the sample conditions per batch are homogeneous.

Data analysis techniques in this study include data reduction, data presentation, and conclusion/verification. Data reduction is done by selecting and simplifying the data obtained in the field. The data obtained were identified and then made a summary, coding to facilitate the search for each unit/data. Then the data are categorized and data that are not relevant to the research problem/focus and research sub-focus are set aside. The presentation of the data in this study was carried out as simple as possible, transparent, and easy to understand, to then be used as structured information in drawing conclusions and taking action. In the next stage, concluding or verification is done by looking for relevant data, noting regularities, patterns, explanations, possible configurations in the form of prepositions. The meaning that emerges from the data obtained is then tested for correctness and suitability so that it is truly valid. The accuracy of the conclusions depends on the accuracy and sharpness of the imagination when performing data analysis.

\section{RESULTS AND DISCUSSION \\ 1. Coach Perspective on Basic Training}

Based on the tabulation results, the descriptive statistics of coach respondents are $25 \%$ female and $75 \%$ male, with the majority level of education (100\%) being masters/strata 2, and the ranks of the respondents as a whole (100\%) are at the level administrator.

From the results of the interview, the whole Coach answered the commitment towards developing the completion of tasks Coachee by trying to help the Coachee to be able to complete its actualization report properly, by communicating via the application Whats Appmessengers and others, paying attention to the completion of participant assignments, providing special time to serve consultations with Coachee. This shows that commitment Coach's to helping towards the development of task completion is 
Coachee's very high. This is indicated by the answer Coach by providing a special allocation for his Coachee.

This result is relevant to previous research (Suyono, 2015). The success of participants from activities is coaching determined, one of which is the frequency of consultation with training participants in actualizing change projects and the frequency of consultation on activity stages. Based on Jarvis (2008), defines coaching as developing a person's skills and knowledge, so that their performance will improve, and lead to the achievement of organizational goals. This theory is in line with the answers to the results of the interview questions above which show that the commitment Coach to helping towards developing task completion is Coachee's very high. This is indicated by the answer Coach by providing a special allocation for his Coachee. The competence of trainers in facilitating training participants supports the successful implementation of training in research (Djoka, 2018) in line with the results of this study.

In the second question related to how the Coach conducts an assessment, diagnosis, and planning in guidance to providing Coachee, the answer is that before the process coaching, an in-depth interview is carried out to find the abilities of Coachees, after the method is determined coaching which the appropriate for each Coachee different in carrying out their actualization. . The second respondent answered that the guidance for Coachee was based on the reports and enthusiasm of the participants. The third respondent answered that guidance to Coachee was carried out by providing directions according to the participant's function assignments. And the last respondent answered that the guidance for Coachee was done by looking at understanding the Coachee personal first, then giving directions in a language that could easily understand Coachee.

Followed by the third question related to how the Coach conducts regular face-toface meetings and provides feedback on the actualization development coachee. It was found that the answer was that face to face was carried out while the Coachee was in the training environment, in this case, it depends on the needs of the Coachee itself as well as face-to-face meetings with the coach. Apart from face-to-face, the process is coaching also carried out through WhatsApp media to further sharpen input on the actualization that will be carried out by the coachee. The second respondent responded by setting the schedule and approval of each Coachee. The third respondent answered to carry out the dialogue clearly so that the participants could complete the actualization properly.

While the last respondent answered face-to-face which was done as minimum as possible by maximizing online media for guidance and providing feedback. If online guidance is not understood enough, Coachee will do it face to face. The results above are in line with the theory put forward by Jarvis which distinguishes between coaching and mentoring, it is explained that in coaching the general relationship has a certain duration, is generally more structured and the meetings are scheduled regularly, short term (limited by time) and focuses on specific developmental areas/problems. , the focus, in general, is on development/problems at work, the agenda is focused on achieving 
specific goals and is immediate and coaching is more oriented towards development areas/problems.

Likewise, what is meant (Jarvis, 2008) that coaching is a routine and structured meeting, which is different from activities mentoring that are more informal and flexible. Dialogue and face-to-face are carried out during the coachee's training environment and based on the needs of the participants and the meeting schedule is determined after each coachee's approval. Even though this is very similar to activities mentoring, most coaches focus on online consultation through the media, such as WhatsApp messenger, apart from minimizing face-to-face unless it is deemed less than optimal.

Furthermore, in the fourth question related to how the Coach has shown attitudes related to caring for Coachee in conducting face-to-face discussions and meetings during the session, it was Coaching found that the answer was that some respondents answered that they had shown attitudes related to caring for Coachee in conducting discussions because Coach was one of them. As an instrument for the success of the participants in completing the actualization, in addition to being a coach, they also sometimes position themselves as their counsellor which motivates if participants experience difficulties in carrying out the actualization. The second respondent answered because it was the job of the Coach. The third respondent answered because it was his duty as a coach to provide good direction to the participants in completing the actualization. And the last respondent answered because every Coachee has the right to get services coaching maximum. This is in line with Armstrong who stated that coaching is a personal approach (usually one by one) in work to help someone develop their abilities and levels of competence.

Assistance Coach in the success of actualizing changes in training participants is seen from how the attitudes related to the care coachees were developed during discussions and face-to-face meetings during the session coaching as the fourth question of this study. (Glcworld.co.id, 2020) This assesses the role of a coach to help Coachee grow and develop into a competent, independent individual without dependence on the coach in the future. As the overall answer coach's that this is his duty in providing direction to the participants, the role is a coach as an instrument for the successful implementation of participants' actualization, in addition to being a counsellor in motivating if participants experience difficulties in implementing the actualization. Regular meetings are also the right of every coachee to get services coaching maximum.

In the fifth question, what is Coach listening to and providing feedback regarding the development and improvement of actualization Coachee during the meeting, most of the respondents answered the thing same that they had listened and provided feedback regarding the development and improvement of actualization because the input coach was necessary for the perfection of the actualization report. The second respondent answered for the smooth running of the participant's project. The third respondent answered that as a coach must listen more. And the last respondent answered because 
not all participants fully understood the actualization principles. Respondents' answers above support the theory according to Rosinski which states that coaching is an art in helping to launch one's potential to achieve important and meaningful goals. The concept of coaching is a fundamental process carried out by a Coach to a Coachee which aims to develop competencies that are closely related to learning so that participants can produce the best actualization reports.

Followed by the last question related to whether as a Coach has carried out the task of providing implementation and follow-up to the Coachee can we check out the theory of coaching is a very global language in the dictionary is defined as "In a very global language, Coaching is defined as"Coaching, teaching, instructing, advising the team or person to achieve certain goals. "In the questionnaire inquiry found different answers among respondents that the first responders, second, third and fourth both agreed Coach has done its job in providing the implementation and follow-up on Coachee because it got the answer that so far Coach seeks to help with whatever they can so that the Coachee them can complete their actualization and also continue to motivate so that actualization can continue even though basic training has been completed and must provide concrete examples in the implementation of tasks. Whereas the last respondent answered different things that the Coach did not provide implementation and follow-up because the implementation was the responsibility of the participants. Furthermore, in theory, the answers of the last respondents support the theory which states that in Coaching, Coach does not provide solutions for Coachee, but guides them to find solutions through digging from within themselves.

The fifth and sixth questions related to the attitudes coach when at discussion and face-to-face during the session coaching and the form of implementation/feedback in carrying out their duties as a coach are answered by most coaches by listening more, input coach is needed for the perfection of the actualization report. for the smooth running of the participant's project, because as a means of emphasizing understanding the principles of actualization. Besides, the response is coach's needed because the coach must provide concrete examples in the implementation of tasks, efforts to assist them as best as he can coach in completing the actualization and continuity of post-training actualization from training participants.

\section{Coachee Perspective on Basic Training}

Descriptively the composition of the basic training participant respondents consisted of 50\% women and 50\% men, with an average age level of $43.8 \%$ (7 people) aged 26-30 years, as many as $43.8 \%$ (7 people) $>31$ years and as many as $12.5 \%$ (2 people) aged 20-25 years. The majority of participants' education level is a graduate of undergraduate $(90.3 \%)$ and S2 as much as 6.3\% (1 person), with a rank/class level of $90.3 \%$ (15 people) group III-a and 6.3\% (1 person) group III -b. 
The results of the summary of questions on basic training participant respondents are as follows:

\section{a. Commitment Towards Development of Task Completion}

As many as $100 \%$ (16 people) of all respondents answered Yes (often or always) that Coach they take the time to help develop professionalism in a discussion of actualization design. A total of $6.3 \%$ (1 person) of respondents answered No (never done or very rarely). Meanwhile, 31.3\% (5 people) answered sometimes (sometimes). And $62.5 \%$ (10 people) answered yes (often or always). This shows that most of the respondents answered that Coach allows them to discuss with other coaches or other competent people about their actualized design.

A total of $6.3 \%$ (1 person) of respondents answered No (never done or very rarely). Meanwhile, 6.3\% (1 person) answered sometimes (sometimes). And 87.5\% (14 people) answered yes (often or always). This shows that most of the respondents answered that Coach spent time outside the mentoring schedule to discuss actualization tasks Coachee. A total of $6.3 \%$ (1 person) of respondents answered No (never done or very rarely). Meanwhile, 6.3\% (1 person) answered sometimes (sometimes). And 87.5\% (14 people) answered yes (often or always). This shows that most respondents answered that Coach took the time and discussed the development and progress of the actualization task habituation Coachee after assessing the actualization design.

As many as $12.5 \%$ (2 people) answered sometime (sometimes). And $87.5 \%$ (14 people) answered yes (often or always). This shows that most respondents answered that Coach helps Coachee to better understand ANEQA's values in the implementation of actualization tasks which have an impact on the professionalism Coachee as apparatus later in the workplace.

b. Assessment, Diagnosis, and Planning

On Assessment, Diagnosis, and Planning, as many as 18.8\% (3 people) answered sometimes and $81.3 \%$ (13 people) answered Yes (often or always). This shows that most respondents answered that coach there was able to identify and provide targets that they could achieve in actualization. As many as 12.5\% (2 people) answered sometimes (sometimes) and $87.5 \%$ (14 people) answered yes (often or always). This shows that most respondents answered Coach their identified and communicated the consequences if they did not complete the actualization stages.

A total of $6.3 \%$ (1 person) of respondents answered No (never done or very rarely). Meanwhile, $12.5 \%$ (2 people) answered sometime (sometimes). And 81.3\% (13 people) answered yes (often or always). This shows that most of the respondents answered that Coach they have specified what and why should be done by them before meeting their actualization habituation with them. A total of $6.3 \%$ (1 person) of respondents answered No (never done or very rarely). Meanwhile, $18.8 \%$ (3 people) answered sometimes (sometimes). And 75\% (12 people) answered Yes (often or always). This shows that most of the respondents answered that if and when the coach 
finds a need for the actualization of habituation development, the Coach conducts an analysis of the situation and determines the root causes and barriers to habituation.

c. Face-to-Face Meetings and Providing Feedback

Regarding Face-to-Face Meetings and Providing Feedback, as many as $6.3 \%$ (1 person) answered No (never done or very rarely). Meanwhile, $25 \%$ (4 people) answered sometimes (sometimes). And 68.8\% (11 people) answered yes (often or always). This shows that most of the respondents answered that Coach prefers to guard their feelings by speaking softly when giving them feedback.

A total of $6.3 \%$ (1 person) answered No (never done or very rarely). Meanwhile, $12.5 \%$ ( 2 people) answered sometime (sometimes). And 81.3\% (13 people) answered yes (often or always). This suggests that most respondents answered that Coach they're explained to them specifically what the actualized design and habituation their organization expects from their actualization development discussions. As many as $100 \%$ (16 people) of all respondents answered Yes (often or always) when Coach gave specific feedback about suggestions for actualization improvement and future development when holding meetings.

A total of $6.3 \%$ (1 person) answered No (never done or very rarely) and $93.8 \%$ (15 people) answered Yes (often or always). This shows that most of the respondents answered that coach their helped to identify barriers to future development and informed about ways to solve problems in the after habituation meeting. A total of $6.3 \%$ (1 person) answered sometimes (sometimes) and 93.8\% (15 people) answered yes (often or always). This shows that most of the respondents answered that Coach provided honest feedback and helped them to better understand how behaviour and performance were perceived in the organization.

\section{d. Concern}

About indicator Concern, as many as 6.3\% (1 person) answered No (never done or very rare). Meanwhile, 56.3\% (9 people) answered sometimes (sometimes). And $37.5 \%$ (6 people) answered yes (often or always). This shows that most of the respondents answered that Coach sometimes ensures privacy and allocates a special allocation for them when meeting with Coachee.

As many as $12.5 \%$ (2 people) answered sometimes (sometimes) and $87.5 \%$ (14 people) answered yes (often or always). This shows that most of the respondents answered that coach always asks about their perspective, then carefully he will discuss to equalize the perception in the discussion of actualization design or habituation. A total of $6.3 \%$ (1 person) answered sometimes (sometimes) and $93.8 \%$ (15 people) answered Yes (often or always). It shows most respondents answered that Coach they always pay attention and consider their perspectives d-actualization discussion draft or habituation.

As many as 25\% (4 people) answered Sometimes (sometimes) and 75\% (12 people) answered Yes (often or always). This shows that most respondents answered 
that Coach shows that Coach is caring and caring through nonverbal behaviour (facing them directly, looking into their eyes, etc.) when meeting them. A total of $6.3 \%$ (1 person) answered sometimes (sometimes) and 93.8\% (15 people) answered Yes (often or always). This shows that most respondents answered that Coach was positive during the session coaching where the Coach communicated his beliefs based on the ability Coachee's to achieve mutually agreed goals and objectives.

e. Listening and Giving Feedback

About Listening and Giving Feedback, on the first question, as many as $12.5 \%$ (2 people) answered occasionally. And 87.5\% (14 people) answered yes (often or always). This shows that most respondents answered that Coach encourages to raise problems openly and honestly in actualization development meetings.

As many as $25 \%$ (4 people) answered sometimes and 75\% (12 people) answered Yes (often or always). This suggests that most respondents answered that Coach encourages a two-way discussion by asking them to present their perspectives and suggestions on areas for continuous actualization development and improvement. As many as $12.5 \%$ (2 people) answered sometimes and $87.5 \%$ (14 people) answered yes (often or always). This shows that most respondents answered that in meeting with Coachee, the Coach their concentrated and listened to their explanations carefully so that the Coach would understand what they said in the meeting.

A total of $6.3 \%$ ( 1 person) answered No (never done or very rarely). Meanwhile, $6.3 \%$ ( 1 person) answered sometimes (sometimes). And $87.5 \%$ (14 people) answered yes (often or always). This shows that most respondents answered that Coach their made sure that he had understood everything they explained through exhibiting behaviours such as: concentrating, asking again to check his understanding of something.

f. Implementation and Follow-up

On Implementation and Follow-up, as many as 6.3\% (1 person) answered No (never done or very rarely) and 93.8\% (15 people) answered Yes (all ring or always done). This shows that most of the respondents answered that Coach their revised their draft actualization reports and allowed time for coaching further.

A total of $6.3 \%$ (1 person) answered No (never done or very rarely). Meanwhile, $12.5 \%$ ( 2 people) answered sometime (sometimes). And 81.3\% (13 people) answered yes (often or always). This shows that most respondents answered that Coach their regularly reviews with them their progress in the actualization phasing. A total of $6.3 \%$ (1 person) answered No (never done or very rarely) and 93.8\% (15 people) answered Yes (often or always). This shows that most of the respondents answered that Coach evaluates their actualization phasing and reinforce each of the steps.

A total of $6.3 \%$ (1 person) answered No (never done or very rarely) and $93.8 \%$ (15 people) answered Yes (often or always). This shows that most of the respondents answered that Coach they always help including discussing with them the obstacles faced and ways to implement improvements in implementing phasing. A total of $6.3 \%$ 
(1 person) answered No (never done or very rarely). Meanwhile, $6.3 \%$ (1 person) answered sometimes (sometimes). And 87.5\% (14 people) answered yes (often or always). This shows that most of the respondents answered that Coach as a whole monitor their design progress and their actualization regularly.

At the end of the research questionnaire, several respondents answered Category VII (additional). Other categories related to the role of Coach, the answer was found that the need for the Coach to provide consultation on actualization plans outside of working hours; The Coach is always willing to listen and give advice at any time without being stuck with time, always actively encourages the Whatsapp group specifically for guidance Coach the appointed and always reminds Coachees to help each other in the actualization process; Coach hopes that the induction report will be independently produced and produce perfect results; should Coach have given Coachee more time to discuss even though they cannot be face to face, at least through Whatsapp and others; Coach is patient while guiding Coachee and appreciates the actualization report Coachee.

This study has limitations, especially in terms of the number of respondents, so that the sharpness of the analysis and presentation of the data still needs to be developed. This is also marked by the presence of most respondents who gave suggestions so that this questionnaire could be used as feedback for Prospective Civil Servants to the Coach, as well as a benchmark for both Candidate Apparatus and Coach as Candidate Apparatus supervisors in mentoring before and after actualization and habituation so that it can serve as an evaluation. for the person Coach to continue to improve its services to the state civil apparatus and society in particular. Meanwhile, other suggestions so that this questionnaire can improve the performance coach's so that it is more totality in guiding a candidate apparatus.

\section{CONCLUSION}

From the results of this study, it is concluded that the role of the coach in carrying out the role of coaching the coachee is indicated by the majority of respondents answering that the intensity of the coach is quite high in mentoring the coachee, but several things need to be optimized, namely, from all of these categories, it is indicated several respondents answered sometimes and not as many as approximately 1 to 4 people, even 9 people in Category IV Concern. This needs to be of particular concern to further education and training so that the optimization of the role of the coach can be felt by the training participants to produce graduates of the candidate apparatus education and training who are competent and produce professional public servants in the Samarinda City Government.

Based on the previous explanation, the following recommendations can be given: 1) The Coach should allow Coachee to discuss their actualization design with other mentors or other competent persons to provide ample input and reference on their actualization. 2) In the category of Assessment, Diagnosis, and Planning, it is hoped that 
the Coach will be able to identify and provide targets that can Coachee achieve in actualization and be able to analyze the situation and determine the root causes and obstacles when going to habituation. 3) A Coach can keep feelings Coachees more by speaking softly when giving feedback to Coachee to create good communication and relationship bonds to create positive encouragement for Coachee to be more enthusiastic in completing actualization. 4) Coach is more concerned with providing privacy and special time allocation attentively through nonverbal behaviour (facing directly, looking into the eyes, etc.) to each Coachee during coaching so that the Coachee is more comfortable and free to convey personal ideas regarding their actualization. 5) The coach is expected to listen more to Caochee's perspective on areas for continuous actualization development and improvement. 6) In the implementation and follow-up, it is hoped that the will periodically Coach conduct a joint review of progress Coachee's in the actualization stages. 7) The role of the coach in increasing the competence of training participants is very important, therefore the coach needs to be more focused and persistent in guiding training participants during the activity process continuously and comprehensively. 8) In the future, the organization can carry out employee competency development based without a budget by using a scheme, coaching namely between direct superiors as coach and staff/ subordinates as a coachee. 9) Regarding competency development in the realm of employees to improve employee performance, organizations can form a team coaching at the Samarinda City Personnel and Education and Training Agency as a pilot project in synergy with Lecturers, Assessor, Personnel Analyst and related Structural Officials to create a platform coaching clinical intended for direct superiors/ leaders to be able to coach their subordinates assisted by a team coaching internalin the implementation of coaching.

\section{ACKNOWLEDGMENTS}

For the completion of this research, I would like to thank the National Institute of Public Administration the Republic of Indonesia, as the organizer of the Middle-Level Entrepreneurship Training (Batch IV) at the Center for Training and Development and Study of Decentralization and Regional Autonomy, parents and siblings who have to provide support with both material and non-material, friends and all parties who have helped.

\section{REFERENCES}

1. Armstrong, M., \& Taylor, S. (2014). Armstrong's Handbook of Human Resource Management Practice: Edition 13. Kogan Page.

2. Jabar, B. P. (2018). Inovasi Menuju Corporate University. Jurnal Inspirasi, 1-648.

3. Djoka, P. P. (2018) 'Efektivitas Pembelajaran Pendidikan dan Pelatihan Latihan Dasar (LATSAR) Melalui Coaching Fasilitator Pada BPSDMD Provinsi Nusa Tenggara Timur', Jurnal Good Governance. 
4. Fraser, R. (2007). Developing an Effective Performance Management System. Retrieved from http://www.hscorp.ca/wpcontent/uploads/2011/12/Developing_an_Effective_Performance_Management_Syst em.pdf.

5. Kimball, D. (2018). Performance Management and Appraisal. Cases in Human Resource Management, 41-47.

6. LANRI. (2020). Pedoman Coaching, Mentoring dan Konseling.

7. Suyono. (2015). Peran Coach dalam Meningkatkan Kompetensi Peserta Diklat Kepemimpinan. Jurnal Pendidikan Humaniora, 3(3), 172-177.

8. Triati, E. (2019). Optimalisasi Peran Widyaiswara dalam Pelaksanaan Pendidikan, Pengajaran, dan Pelatihan. Quantum: Jurnal Ilmiah Kesejahteraan Sosial, 14(1), 42-50. 